\title{
MACROECONOMIC CYCLE MADE VISIBLE IN REAL TERMS AS PROTECTION AGAINST ASSET ILLUSION
}

\section{Uwe Bergold*}

\begin{abstract}
The current historically unparalleled global debt crisis and the resulting momentous valuation anomalies notably affecting the stock and bond markets (the historically low-interest rate level) are making it increasingly difficult for both institutional and private asset managers to generate an actual yield above the inflation rate. The problems with building wealth, and hence with pensions plans, first began at the turn of the millennium when the burst of the largest stock market bubble of all time firmly put the price distortions of assets into the public eye. This milestone also marked the beginning of a secular bust phase, which has been on a real gradual downtrend and despite nominal price increases is still ongoing today. However, this problem only becomes visible upon real evaluation, in ounces of gold. Contrary to the ubiquitous nominal view in uncovered paper currencies, only this real view, valued in ounces of gold, protects both private and institutional investors from an illusion of wealth.
\end{abstract}

Keywords: global debt crisis, stock market bubble, asset illusion, monetary units of measure, boom and bust cycle, Shiller P/E Ratio, Gold, paper currencies, inflation

JEL Classification: E32, E50

\section{Introduction}

Relentless expansionary monetary policies, i.e., overly low interest rates for overly long periods, have led and will continue to time and time again lead to macroeconomic boom and bust cycles. The central banks' interference with the pricing of money (interest rate development), in combination with today's fractional reserve banking system, will always lead to a loan-financed excessive boom, followed by a contrasting bust (Hayek, 1976). The market's "natural credit squeezes", i.e., a currency backed by gold and commodity credit lending - the use of savings (customer deposits) for a loan - went out of style decades ago. It is the supply of ever more excessive bank circulation credit to the national economics, above and beyond the commercial banks' deposits, which ultimately leads to the recurrent economic boom and bust phases (Mises, 1924).

The current, historically unparalleled global debt crisis and the resulting momentous assessment anomalies in all three interest-bearing asset classes - equities, real estate and bonds - make it increasingly difficult for institutional financial intermediaries (pension funds, bond funds and endowment policies) and banks to generate actual yield for their customers above the inflation rate. Business history is full of examples showing that debt crises always culminate in mass expropriation (Plumpe, 2014).

* University of Economics, Prague, Faculty Business Administration (uwe.bergold@grinvest.de). 
The problems with building wealth, and hence with retirement plans, first started at the turn of the millennium, when the burst of the largest stock market bubble of all time brought the price distortions of the assets firmly into the public eye. Since 2000, standard stock markets all over the world have been faced with the problem of generating inflation-adjusted positive earnings in spite of dividend payments. Even the global real estate sector, which driven by the policy of a cheap money burst seven years after the stock market bubble due to momentous over-evaluation, is despite its recovery, also having difficulty generating sustainable earnings in real positive terms. Finally, a look at the rates for fixed-income securities, the bond market, also shows a momentous bubble characterised by historically low interest rates (Shiller, 2015).

This means that even the bond market will not allow the generation of real earnings in the future, no matter how badly the financial intermediaries need these earnings for building wealth and retirement plans for their customers. In the prevailing circumstances, even banks are finding it increasingly difficult (with the interest margin approaching zero) to properly keep up their business operations. Therefore, it is all too understandable that general wealth building and the concept of today's private and corporate pension planning are faced with major challenges. To actually visualise the bust phase (the contraction phase) within macroeconomic cyclical fluctuations, it is necessary to focus on the real issue - i.e., the inflation-adjusted - and not the nominal issues. Only this real consideration (e.g. by valuing asset classes in ounces of gold) protects both private and institutional investors from an asset illusion.

\section{Monetary Units of Measure - Nominal versus Real Valuation}

The development of monetary units has been nurtured for thousands of years by the barter economy and legislation in order to create a medium for exchange; the medium called money. Money also serves as a basis for measuring all kinds of goods and services. This development of a measuring scale has helped to structure economic theory and make it accessible to empirical testing. The evolution of money is an interactive process developed by human judgment and experience and as a medium for measurement. This process has helped to create the framework for incorporating both philosophy and mathematics into the challenging science of the science of economics (Saaty, 1980). The three basic functions of money are a means of exchange, a store of value, and as a unit of account. Money as a means of exchange has obviated the risk of a "double coincidence of wants". A store of value is an asset which maintains its purchasing power over time. A unit of account is a unit used for recording prices and keeping them in the books. The prices are quoted in US dollars and cents and are thus the units used to measure the money supply (Dornbusch, Fischer and Startz, 2014).

Until August 1971, the US dollar had been backed by gold. Ever since that time, US currency has been pegged to nothing. It is important to understand that the US dollar before 1971 has nothing in common with the US dollar after 1971. Ever since the abolition of the gold exchange standard, we have been experiencing structural inflation in all currencies worldwide. After all, monetary units are used as a standard for deferred payments in long-term transactions such as loans. The problem is that the measurement results will deviate, depending on which money is looked at: whether fiat paper currency (since 1971) or gold-backed currency (before 1971). "For people in soft currency countries 
(e.g. India, Turkey, Indonesia, South Africa, Argentina, Brazil) ..., gold as a measure of value will always play a pivotal role" (Gburek, 2003, p. 45).

Figure 1 | S\&P in USD (black) versus S\&P in ounces of GOLD (red) indexed to the monthly closing price for the period January 1881 until December 2017

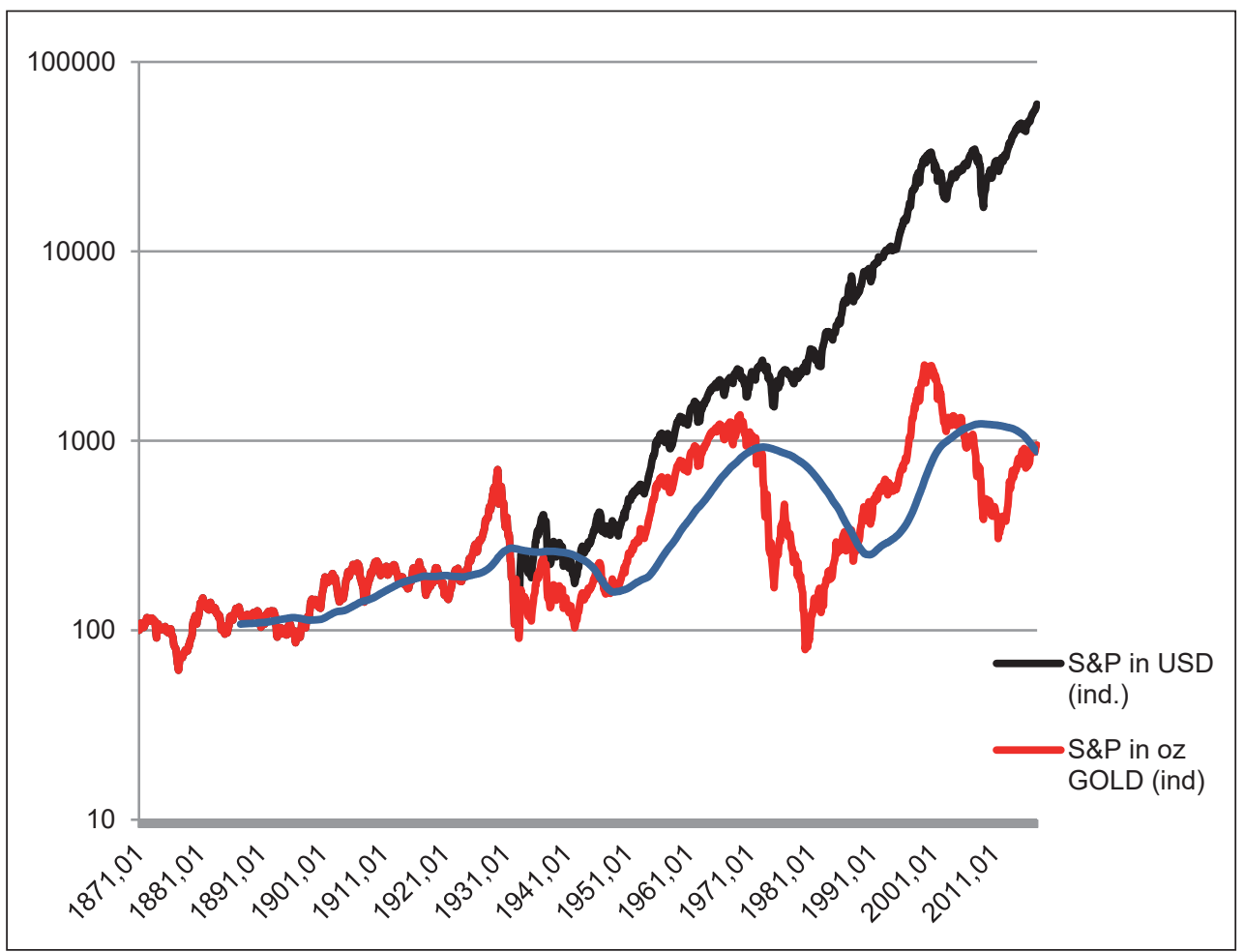

Source: Author’s own processing

A good example is the US stock market's S\&P Index priced (a) in US dollars (nominal valuation) and (b) in ounces gold (real valuation) (see Figure 1). The figure shows the S\&P Index priced (a) in US dollars (black) and (b) in ounces of gold (red). Since 1971, the year the gold exchange standard was abolished, the two graphs have been diverging significantly. Faced with the costs of the Korean and Vietnam war, former President Richard Nixon abolished the obligation to exchange the US dollars of foreign central banks for gold. This caused the system of fixed exchange rates to collapse, and the so-called Bretton Woods currency system disintegrated (Baader, 2010). The US dollar has lost $97 \%$ of its value in gold since that time. Therefore, it is important, when conducting long-term historical analyses from before 1971, to take this monetary component (i.e., the divergence between the two currency approaches) into account. 


\section{Visualisation of the Macroeconomic Cyclical Fluctuations}

The secular shifts between the "boom" and "bust" phases (macroeconomic cyclical fluctuations) can be distinctly visualised by taking a long-term look at fundamental assessment ratios. The example of choice is the "Shiller P/E Ratio" also known as "CAPE" (Cyclical Adjusted Price Earnings Ratio). In contrast to the conventional P/E ratio, CAPE is adjusted for the medium-term economic cycles. CAPE's two designers, Robert Shiller and John Campbell, achieved this by dividing the real (inflation-adjusted) S\&P composite stock index by the moving average of the index's real corporate profits over the past ten years. The price-earnings ratio indicates how expensive the stock market is in relation to an objective measure for the earning power of companies. The Shiller P/E Ratio, as opposed to the conventional PER, uses average earnings over the last decade to smooth out the frequent cyclical upturns and downturns that typically occur over the course of medium-term business cycles (Shiller, 2015).

Figure 2 | Shiller P/E Ratio (blue) including moving average (red), recorded monthly for the period of January 1881 until December 2017

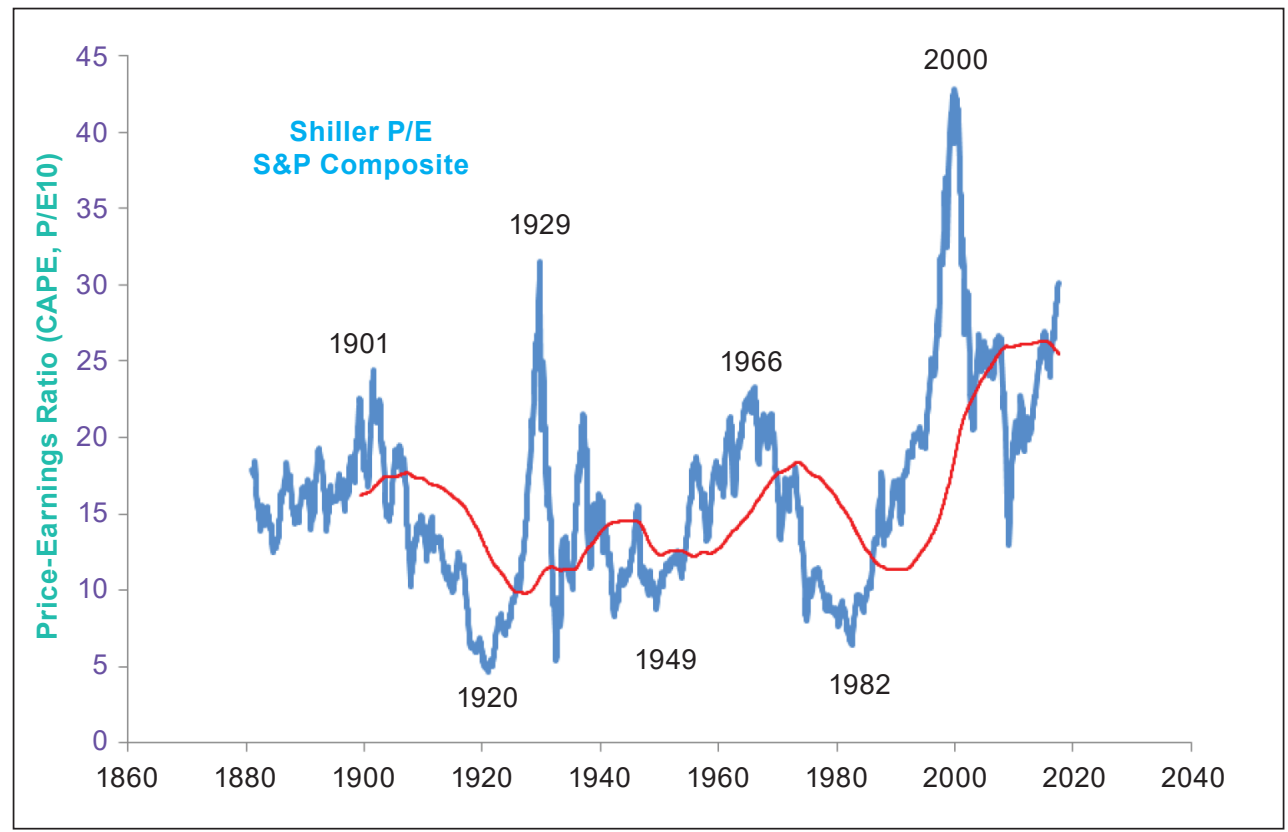

Source: Shiller (2017; edited)

Figure 2 shows the original Shiller P/E Ratio for the period of January 1881 until December 2017. A moving average of 220 months (18.3 years) was added. Whereas a price or value never represents more than a fleeting snapshot of the current consensus of large crowds of people, a moving average (MA) works like a composite photograph. The most important message conveyed by a moving average is its direction of inclination. A rising moving average shows that the finance community is optimistic, whereas a declining moving average visualises the negative mood of the stock exchange participants. 
This functionality is evident both in share price development and in the trend of the price-earnings ratio. If the investors' mood becomes more positive than before, share prices (values) will increase above the moving average. If, conversely, their mood becomes more negative than before, share prices (values) will drop below the moving average. A moving average should be approximately half the length of a possible cycle (Elder, 1999). As the average length of a macroeconomic cycle (boom plus bust phase) is approximately 37 years, a moving average of 220 months (18.3 years) was chosen for Figure 2. A look at this figure visualises a cyclical movement starting in 1881 (see the moving average in Figure 2) and moving back and forth like a sine wave from one extreme (1901, 1929, 1966 and 2000 booms) to the other (1920, 1949 and 1982 busts). The macroeconomic cyclical fluctuations are also evident from the "real" valuation of the S\&P Stock Market Index in ounces of gold, albeit not from the nominal valuation in US dollars, due to the 1971 abolition of the gold currency standard (which has subjected the global stock markets, and hence global economics, to structural inflation ever since) (see Figure 1).

\section{Validity of the Watershed Points in Cycles for Future Earnings}

It is notably the upper cycle reversal points, from the boom phase ("economic summer") to the bust phase ("economic winter"), which are relevant for investors to protect their assets. The Shiller P/E Ratio reached peak levels three times in the previous century. The fourth historically unparalleled peak occurred precisely at the turn of the millennium (see Figure 2). The first secular bull market peak occurred in June 1901, when the CAPE was at 25.2. After that turning point, the stock index lost $67 \%$ of its value by June 1920 . For the next 15 years following June 1901, the effective average yield from equities (including dividends) was around 3.1\% annually. For the next 20 years following June 1901, the calculated effective average yield (including dividends) was $-0.2 \%$ annually. The second secular turning point occurred in September 1929, with a CAPE of 32.6. After that turning point, the S\&P Stock Market Index lost a massive $81 \%$ of this value by June 1932. For the next 15 years, the effective average yield from equities (including dividends) was at $-0.5 \%$ annually, and at $-0.4 \%$ annually for the next 20 years. Adjusted for inflation, it took the stock index until December 1958 to regain the value of September 1929. The third secular bull market peak of the last century occurred in January 1966, at a $\mathrm{P} / \mathrm{E}$ ratio of 24.1. Once again, the stock market lost tremendous ground in the aftermath and in December 1974 was 56\% lower than in January 1966. The actual return on shares purchased during the bull market peak (including dividends) averaged $-0.5 \%$ annually for the next fifteen years, and $1.9 \%$ for the next twenty years. Adjusted for inflation, it took the shares until May 1992 to reattain the level of January 1966 (Shiller, 2000). After neither of the three macroeconomic cycle reversal points did the S\&P stock index manage to generate positive real earnings during the subsequent 15 to 20-year period. After the last two turning points in 1929 and 1966, it took nearly 30 years every time to reattain the prior macroeconomic bull market peak, adjusted for inflation. 


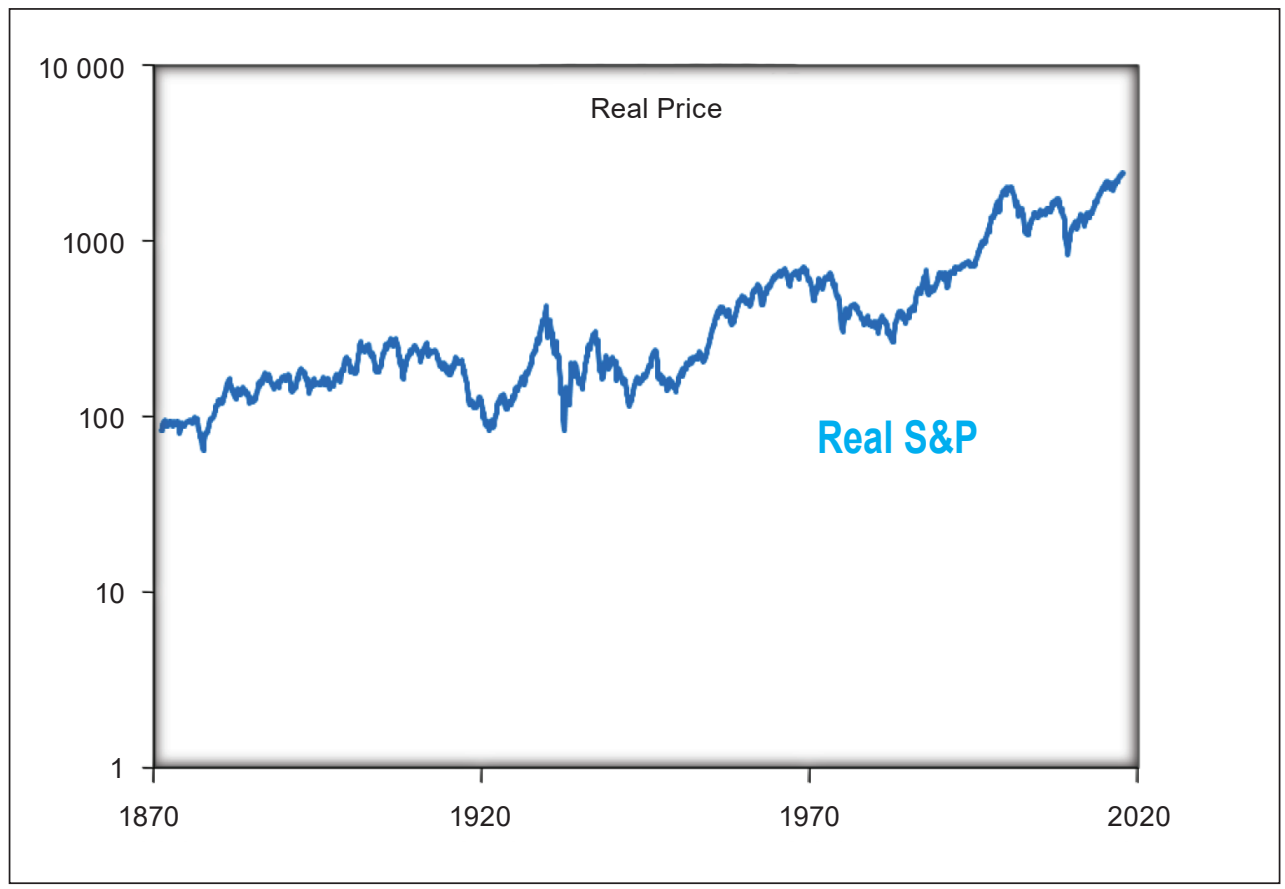

Source: Shiller (2017)

The fourth secular bull market peak (the most recent macroeconomic cycle reversal point) was generated by the Shiller P/E Ratio precisely in December 1999, at a value of 44.2 (see Figure 2). This means that the S\&P stock index commenced its secular bust phase ("economic winter") precisely at the turn of the millennium. Despite the two stock market crashes from 2000 until 2003 and from 2007 until 2009, the index reached a new nominal record high in December 2018. Adjusted for inflation - and calculated at the US consumer price index (CPI) - the shares are listed only marginally above the cyclical peak at the turn of the millennium (see Figure 3). Considering that the CPI calculation method was amended repeatedly during the 1980s and 1990s, it is difficult to make historical comparisons with data from before 1980 . As the more recent data is calculated at a lower inflation rate than the data before 1980, the real data since the early 1980s appears more positive than that prior to 1980 .

The change in the inflation calculation distorts not only the real stock market presentation, which is intended to give a lead over the real economy, but also the real presentation of the gross national product. Figure 4 shows different periods of US recession. If one compares the official recessions (dark grey fields) with the recessions (light grey fields) resulting from the old inflation calculation method used before 1980 (corrected GDP deflator), one sees, in addition to the equity bullish illusion, also an illusion of US economic growth. Just as the real representation is distorted in the stock market - due to the changed calculation methods - this distortion is also reflected in the representation of US economic growth (see Figure 4). 


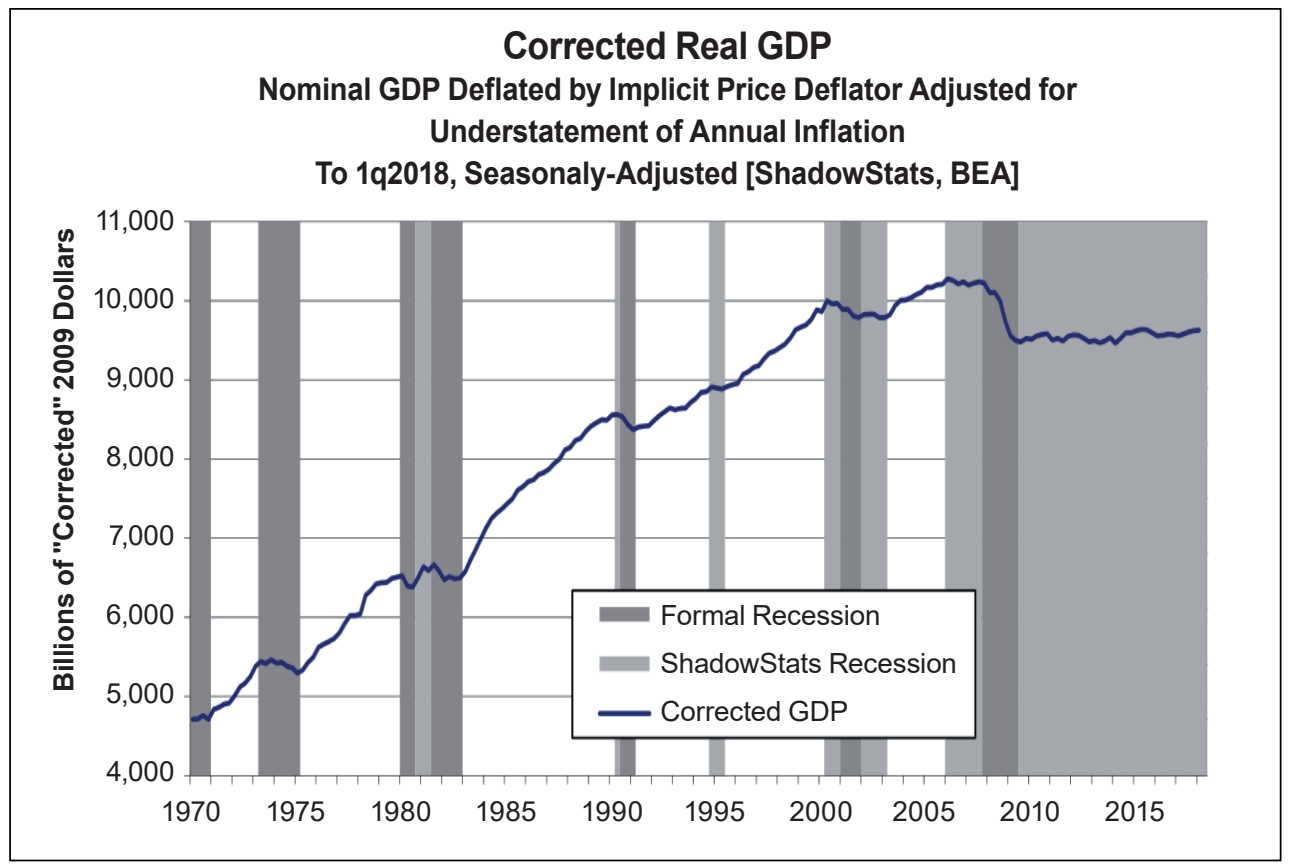

Source: Diekmeyer (2018)

A realistic approach to addressing this problem is to present the assets undervaluation not in US Dollars, but in ounces of gold (see Figure 1). Until 1971, with a few brief interruptions during the American Civil War and the Second World War, the US Dollar was due to the existing gold standard or gold exchange standard equated to gold at a certain ratio.

A look at the S\&P Stock Market Index in US Dollars and in ounces of gold (see Figure 1) clearly visualises the parallelism of both graphs until 1971. After 1971, the macroeconomic cyclical fluctuations are no longer nominally visible due to the structural inflationary pressures. Since then, there appears to have only been a single primary upward trend on the stock exchanges, apart from a few interruptions of greater or lesser duration. However, when returning to valuating stock markets in ounces of gold, as was customary until 1971 in gold-backed paper currency, it once again becomes possible to visualise the overriding boom and bust phases (see Figure 1). This makes it obvious that the S\&P Stock Market Index, despite its nominal record highs in US Dollars, has "realistically" lost more than $65 \%$ of its value in ounces of gold since its last cyclical peak at the turn of the millennium.

When asked in 1994 by New York State Congressman John LaFalce whether the gold price was not just an expression of crowd psychology, Alan Greenspan, the head of the US Federal Reserve with the longest term in office, told him: "I don't think so. Gold is a different kind of commodity because virtually all the gold ever produced is still around. Therefore, changes in the level of production have very little effect on the ongoing 
price. Which means that it is virtually wholly a monetary demand phenomenon. Gold is, therefore, a standard of value which has over the years proven its worth as a reliable signpost of inflationary expectations and a very good indicator. The gold price is a much better indicator than commodity prices or many other things" (Gburek, 2003, p. 161).

\section{Approaches to Explaining the Cyclical Fluctuations on the Macro Level}

Whereas behavioural finance literature often explains the phenomenon of macroeconomic boom-bust cycles ("positive" and "negative" speculative bubbles) on the capital markets (stock, bonds and real estate markets) as the result of investors' psychological and behavioural decision-making patterns, it is, nevertheless, necessary to have a monetary cloak in order to finance the asset price bubbles. This means that a boom phase will be exacerbated by the overly expansive monetary policies of the central banks. However, they are often barely aware of the excess supply of money because their target variable, the "inflation rate", does not address the capital investment prices (i.e., equities, bonds and real estate), but the prices of goods. As a speculative bubble grows, it becomes necessary to divert an ever-larger portion of the macroeconomic money supply for financing the stock market trading volumes, money which is no longer available for the consumption of goods. This also explains the - ever highly acclaimed as "new" - combination of virtually unchanged prices for consumer goods and exploding prices for assets. The effects of money supply changes on asset price development have, in the meantime, been investigated in various studies and indicate a positive correlation between the two variables (Mezger, Stahl, Eibl, Single and Krauß, 2003).

Understanding inflation not only as a driver of consumer price rises but also of investment price rises helps build the bridge to macroeconomic boom-bust cycles. The consequence of inflation is not so much a rise in consumer goods prices but a rise in the prices, for example, of equities and real estate. An increase beyond long-time comparative figures - price-earnings ratio, dividend yield, or price-book ratio - appears harmless for as long as the economic entities believe in the permanence of changed relations and continue investing in equities and real estate. These bubbles are increasingly fed by the excess liquidity in the system. However, if this liquidity suddenly stops or if the interest rate rises (the price for liquidity), these bubbles may burst overnight, and their knock-on effects may drag an entire national economy into a recession or depression. This kind of bubble scenario can also occur in cases where overly low interest rates make it appear attractive to build capital-goods producing industries, which have to be aborted as soon as the interest rates rise again, making the investment projects unprofitable (Starbatty, 2007). Ludwig von Mises summarised it in a lecture on the causes of the economic crisis: "The periodic recurrence of economic crises is the inevitable consequence of the ever-renewed attempts to push down the market's natural rate of interest by way of banking policies. Economic crises will not disappear until this lesson has been learned: to avoid all manner of boosterism because an artificially engineered boom cannot last forever, but must come to an end sooner or later, and will inevitably lead to crisis and depression" (Mises, 1931, p. 14). 


\section{Summary}

The primary cause of macrocyclics can be postulated as follows: highly expansionary monetary policies, initiated by too low long-term interest rates, have been causing recurrent macroeconomic boom and bust cycles and will continue to do so in the future. The central banks' interference with the pricing of money (monetary policy), in combination with today's fractional reserve banking system, always leads to a loan-financed excessive boom, followed by a contrasting bust.

The problems with building wealth, and hence with pension plans, first started at the turn of the millennium, when the burst of the largest stock market bubble of all time brought the price distortions of the assets into the public eye. This milestone also marked the beginning of a secular bust phase ("economic winter") which has been on a real gradual downward trend and is still ongoing to this date, despite nominal price increases. However, this problem (asset illusion) only becomes visible upon real evaluation, in ounces of gold (see Figure 1).

A particularly impressive example of both evaluation options is the German stock index during the Weimar hyperinflation. This can be evaluated either in nominal German Papiermark currency or in real Goldmark. The differences in the measured values could not be more obvious. Whereas the stock index in unbacked paper money increased by more than 21 trillion per cent, its value - valuated in gold currency - dropped by $74 \%$ during that same period (see Figure 5).

Figure 5 | German stock index in German Papiermark currency (black) and in Goldmark (red) from $01 / 1918$ until 12/1923

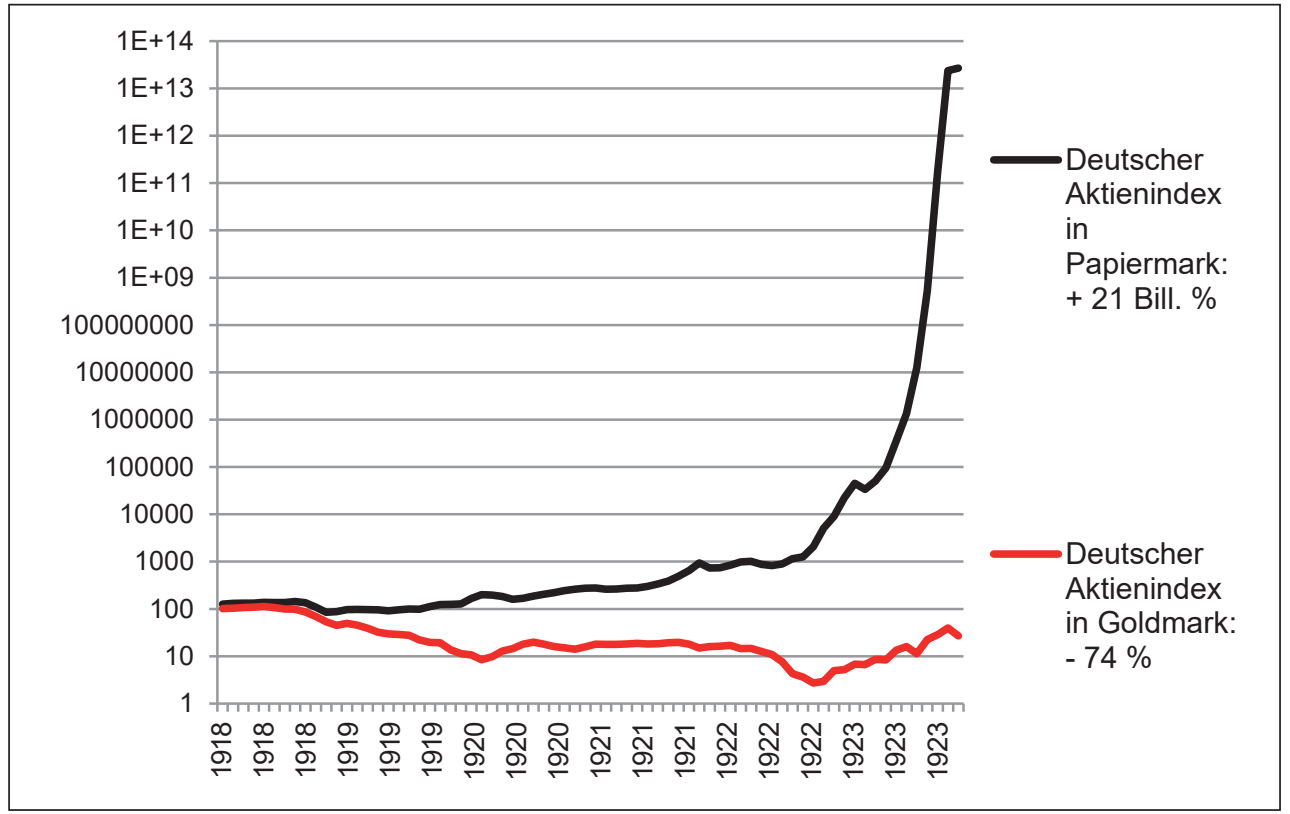

Source: Wikipedia, Aktienindex des Statistischen Reichsamtes (The Stock Index of the Office for Statistics of the German Reich; edited) 
As in the early 1920s in Weimar Germany, the problem of asset illusion within macroeconomic cycles (macroeconomic bust phases) can only be made visible by valuing gold in ounces. At the beginning of the new millennium, when the last macroeconomic top was generated (see Figure 2), we are currently experiencing such an illusion of wealth again worldwide. This can also be seen in the current German share index DAX, which is valued in ounces of gold (see Figure 6).

Figure 6 | German stock index (DAX) in EUR (black) and in ounces of gold (red) from 01/2000 until $09 / 2018$

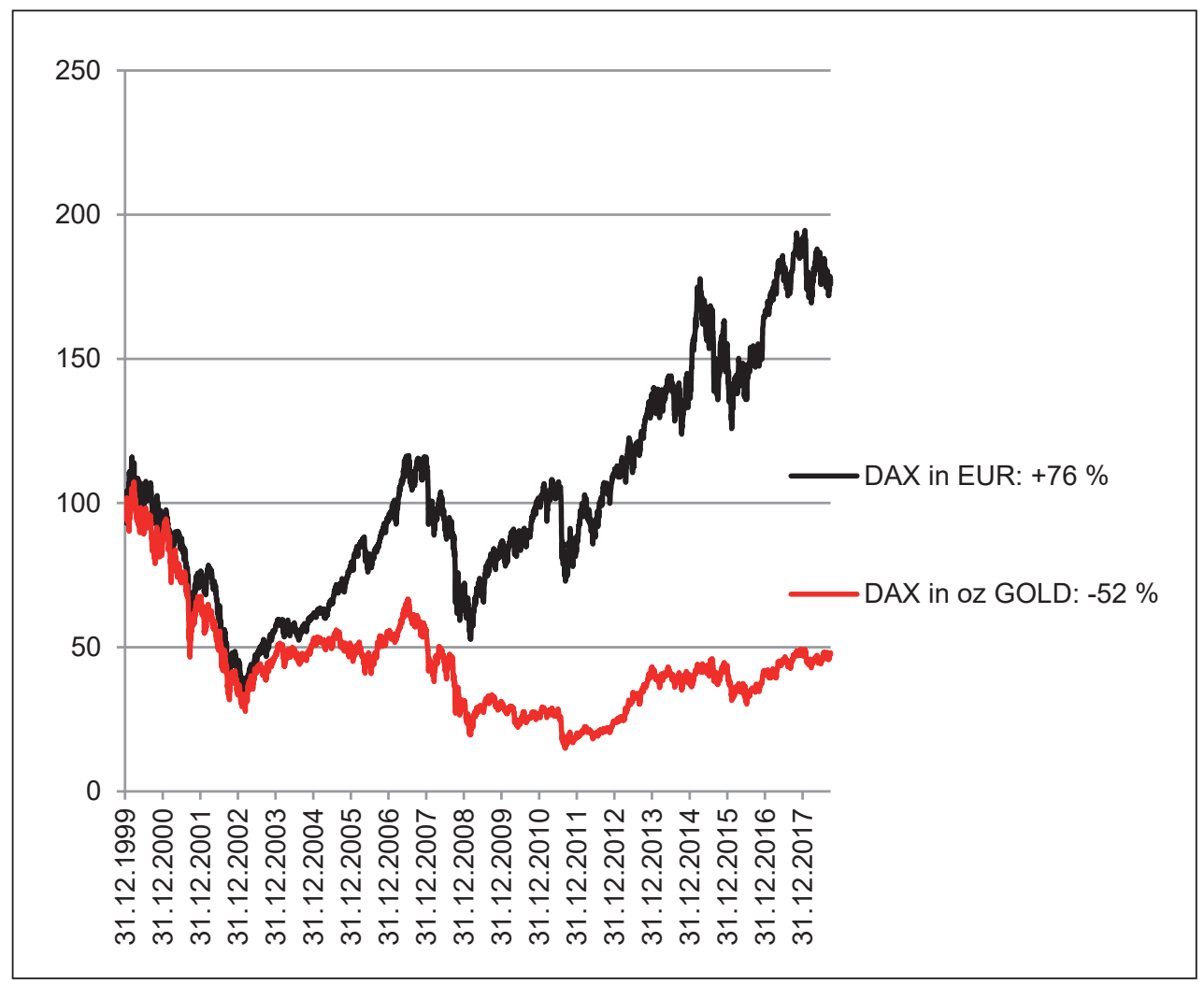

Source: Author's own processing

In summary, it can be postulated that due to uncovered paper currencies and, over time, the changed methods of calculating inflation, investors can only protect themselves from asset illusions during macroeconomic bust phases by valuing their asset shares in ounces of gold. This currently appears to be the only way for investors to visualise the true inflation-adjusted performance of their assets. 


\section{References}

Baader, R. (2010). Money-Socialism. Zurich: Vontobel Foundation.

Diekmeyer, P. (2018). Is the U.S. in a Depression? [online]. Available at: https://www.zerohedge.com/news/2018-06-08/us-depression-how-john-williamsbecame-americas-most-important-statistician [Accessed 11 Jun. 2018]

Dornbusch, R., Fischer, S., and Startz, R. (2014). Macroeconomics. New York: McGraw-Hill.

Elder, A. (1999). Die Formel für Ihren Börsenerfolg [The Formula for Your Stock Market Success]. Munich: FinanzBuchVerlag.

Gburek, M. (2003). Das Goldbuch [The Gold Book]. Munich: FinanzBuch Verlag.

Hayek, F. (1976). Geldtheorie und Konjunkturtheorie [Monetary Theory and Economic Cycle Theory]. Salzburg: Wolfgang Neugebauer Verlag.

Mezger, M., Stahl, M., Eibl, C., Single, G., and Krauß, M. (2003). Megatrend Gold - Neue Entwicklungen [Gold as Megatrend - New Developments]. Stuttgart: Macro Research, BW Bank.

Mises, L. (1924). Theorie des Geldes und der Umlaufsmittel [The Theory of Money and Credit]. Berlin: Duncker \& Humblot Verlag.

Mises, L. (1931). Die Ursachen der Wirtschaftskrise [The Causes of the Economic Crisis]. Tübingen: Mohr Verlag.

Plumpe, W. (2014). Wirtschaftshistorische Überlegungen zu Staatsschulden, Schuldenabbau und deren Folgen [On National Debt, Debt Reduction and the Consequences from the Perspective of Economic History]. [online] Portfolio Institutionell. Available at: http://www.portfolio-institutionell.de/wirtschaftshistorische-ueberlegungen-zustaatschulden-schuldenabbau-und-deren-folgen [Accessed 11 Jun. 2018]

Saaty, T. (1980). The Analytic Hierarchy Process. New York: McGraw-Hill.

Shiller, R. (2015). Irrationaler Überschwang [Irrational Exuberance]. Kulmbach: Plassen Verlag.

Shiller, R. (2017). Online Data Robert Shiller, [online]. Available at: http://www.econ.yale.edu/ shiller/data.htm [Accessed 24 Sep. 2017]

Starbatty, J. (2007). F. A. von Hayek und die "Bubble Economy“ [F. A. von Hayek and the "Bubble Economy"], [online]. Available at: https://ecitydoc.com/download/1-fa-von-hayek-und-die-bubble-economy-joachimstarbatty_pdf [Accessed 24 sep. 2017]

Williams, J. (2017). Shadow Government Statistics - Alternative Inflation Charts, [online]. Available at: http://www.shadowstats.com/alternate_data/inflation-charts [Accessed 26 Sep. 2017] 